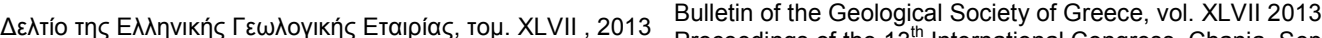

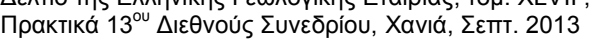

\title{
NEAR-REAL-TIME EVALUATION OF THE EVOLUTION OF A SEISMIC EXCITATION: APPLICATION TO THE JANUARY 8, 2013 LEMNOS SEISMIC SEQUENCE
}

\author{
Teza E. ${ }^{1}$, Scordilis E.M. ${ }^{1}$, Papazachos C.B. ${ }^{1}$ and Karakaisis G.F. ${ }^{1}$ \\ ${ }^{I}$ Department of Geophysics, Faculty of Geology, School of Science, Aristotle University, GR- \\ 54124 Thessaloniki,Greece., eteza@geo.auth.gr,manolis@geo.auth.gr,kpapaza@geo.auth.gr, \\ karakais@geo.auth.gr.
}

\begin{abstract}
Monitoring the evolution of a seismic excitation in near-real-time sense is of high practical importance, as the quantitative results of this procedure may provide useful information to be used for the efficient planning of seismic protection measures. Furthermore, it may provide indications on the future evolution of this sequence, which is extremely important for both the public and authorities. A software package consisting of a number of sub-programs has been developed for this task. The main goal of this software is to obtain a semi-automatic evaluation of the possible evolution of a seismic excitation (sequence) already in progress. To achieve this target, successive determinations of basic parameters that characterize the sequence are performed and respective graphs are produced. In particular, the software automatically provides periodical snap-shots (within time periods defined by the user) describing how the shocks-members of the sequence are distributed in space, time, space-time and magnitude, allowing, this way, to detect possible variations in these parameters that could be connected to normal or non-normal evolution of the sequence. Application of this package has been performed during the recent seismic sequence which occurred SE of Lemnos island with a mainshock of $M=5.9(8 / 1 / 2013,14: 16$ GMT). The snap-shots that described the evolution of the sequence and were produced by the application of the developed software package suggested a "normal" aftershock evolution during the first seven days of the main phase of this excitation.
\end{abstract}

\section{Пєрí $\eta \psi \eta$}

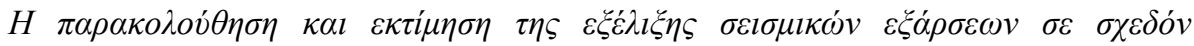

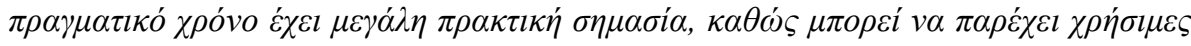

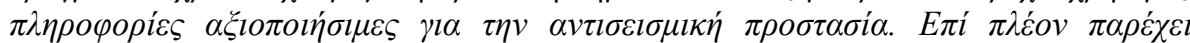

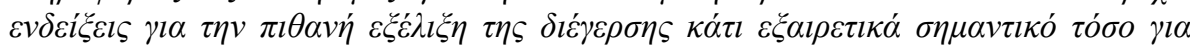

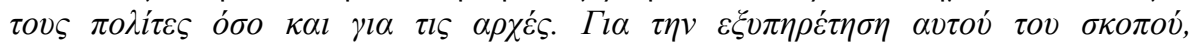

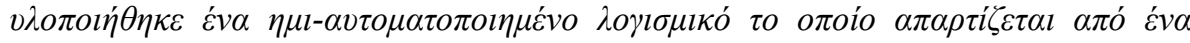

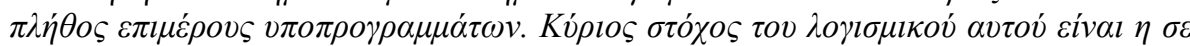

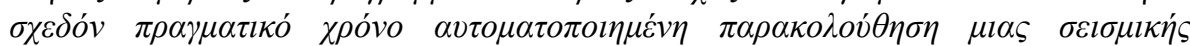

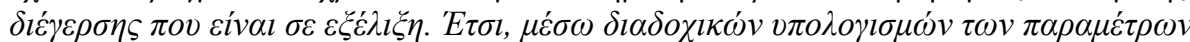

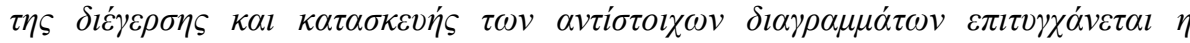

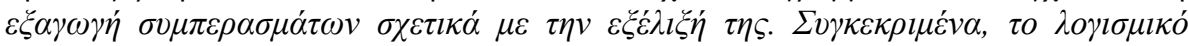

XLVII, No $3-1298$ 


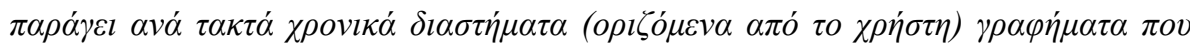

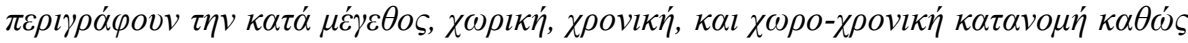

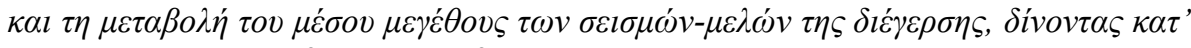

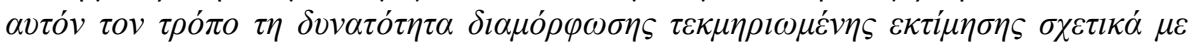

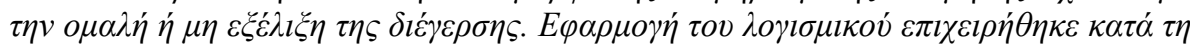

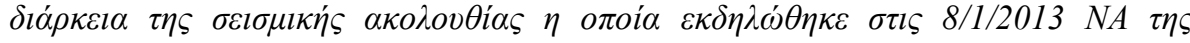

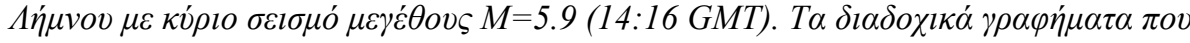

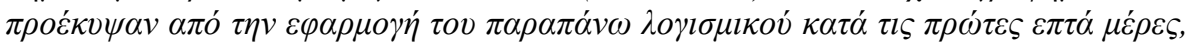

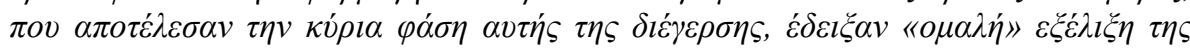

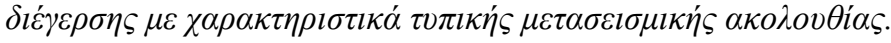

\section{Introduction}

Studies of seismic excitations can provide useful information of practical importance about their evolution. From this perspective, physical and statistical characteristics of their shocks-members such as their distribution in space, time and magnitude contribute to the understanding of the tectonic environment in which they occur and the stress distribution in the area.

Examination of spatial distribution of the earthquake hypocenters of a seismic sequence can provide useful information on both the length of the fault, and the rupture process on its surface. The first relatively accurate determination of epicenters of aftershocks, was performed by Nasu (1929) and concerned the aftershock sequence of the mainshock in Tango, Japan, on March 7, 1927 $(M=7.3)$, focusing on the spatial and time distribution of the events. The study of the space-time distribution can provide indications on the way that the seismic fault ruptured, e.g. it can be assessed if the seismic activity is connected to a unilateral or a bilateral rupture. Such information could be used to "predict" the possible epicenter of a probable ensuing strong aftershock.

The time distribution of the aftershocks of a sequence, that is the rate of their occurrence, gives valuable information on how the sequence evolves with time. The first quantitative study of a seismic sequence was performed for the aftershocks of the mainshock of Nobi, Japan, $(\mathrm{M}=8.0$, 28.10.1891). Omori (1894) observed that the number of these aftershocks decays with time according to the following formula:

Equation 1

$$
n(t)=\frac{k}{t+c}
$$

where $t$ is the time from the main shock, $n(t)$ is the number of aftershocks per time unit and $k$ and c are model parameters. Later studies on the Omori law (Mogi 1962, Ranalli 1969, Papazachos 1974 , etc.) have showed that the number of aftershocks per unit-time roughly depends on the elapsed time from the mainshock according to the relation:

Equation 2

$$
n=n_{1} t^{-p} \Rightarrow \log n=a-p \log t
$$

where $n_{l}$ is the aftershocks generation rate, $n$ is the number of aftershocks occurred within time $t$ from the mainshock and $p$ is a parameter that depends on the physical characteristics of the focal area.

One of the most important relations in seismology is the one between the number and magnitude of the earthquakes that occur within a specific region during a certain time-period. This is the wellknown Gutenberg and Richter (1944) relationship:

$$
\underline{\text { XLVII. No } 3-1299}
$$


Equation 3

$\log N_{t}=a_{t}-b M$

where, $N_{t}$ is the number of earthquakes with magnitude $M$ or larger which occur in the region during a time period of $t$ years, $a_{t}$, is the constant of this relationship for $t$ years and $b$ is a scaling coefficient. The latter is of great importance, since it is directly related to the stress-status of the excited area. It is known that small $b$-values are in general characteristic of fore-shock sequences while large $b$-values are connected to seismic swarms (e.g. Papazachos, 1974).

Another important feature that can be used to describe the excitation's identity is the mean magnitude of its member-shocks. This value should remain relatively constant in a normally evolving seismic sequence, whereas its increase may indicate upcoming strong aftershock (or a new main shock). The validation of the possible evolution of seismic excitations, in near real time sense, can provide useful information that can be used for the efficient organizing of seismic protection measures, since it is well-known that strong aftershocks may cause considerable damage.

In the present work, an effort was made to develop and apply a proper software, consisting of a number of sub-programs, in order to study the evolution of seismic sequences. The main goal of this software is to offer to the user the ability to automatically monitor the evolution of seismic excitation in a near real-time sense. This is achieved through successive calculations of parameters which reveal the excitations' identity with simultaneous production of relative graphs, plots and maps.

As a case-study we selected the strong earthquake of magnitude $M=5.9$ which occurred in the seaarea SE of Lemnos island on the $8^{\text {th }}$ January 2013 (Figure 1) and its aftershock sequence.

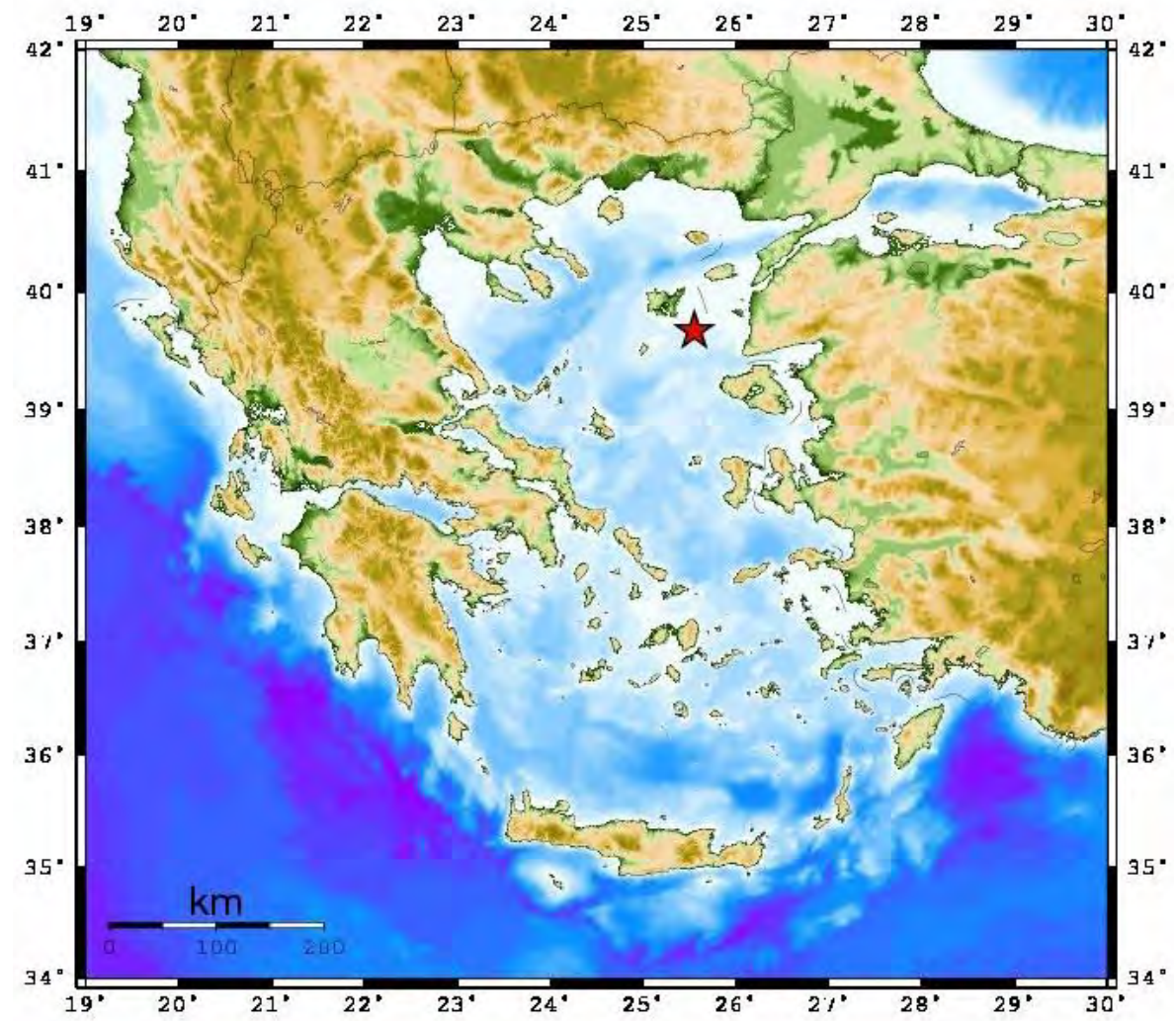

Figure 1- Epicentre map of the main shock of Lemnos 08/01/2013, 14:16 GMT, M=5.9.

$\underline{\text { XLVII, No } 3-1300}$ 


\section{Data}

A prerequisite for the automated software which monitors the evolution of seismic sequences is an earthquake data-file (a catalogue of earthquakes). The main source for this database to be used in the analysis is the automatically recorded and analysed data through the freely distributed SeisComP software (http://geofon.gfz-potsdam.de/geofon/seiscomp, http://www.seiscomp3.org) that operates at the Seismological Station of the Geophysics Department of the Aristotle University of Thessaloniki (AUTH). This software detects and analyses earthquakes automatically, typically within less that $1 \mathrm{~min}$ after their occurrence, therefore, the database is updated in nearreal-time sense. The quality of the focal parameters provided this way is sufficient for the purpose of monitoring a seismic excitation. However, it is well known that automatic locations are not as accurate as the manual ones. For that reason, a procedure was applied to import data of manually analysed earthquakes by replacing in the data-base the corresponding automatic locations. As sources of the manually analysed earthquakes we considered the preliminary bulletins (catalogues) of AUTH and of the Institute of Geodynamics of the National Observatory of Athens (NOA).

\section{Software Configuration and Parameters' Determination}

\subsection{Software Configuration}

The procedures executed by the software, after the necessary data file has been imported (namely the list of earthquakes that created), are outlined below:

- A theoretical circular region is defined, which is centred at the manually relocated epicentre of the main shock and has a radius proportional to its magnitude. The earthquakes enclosed within this circle are automatically selected, in order to create the catalogue of the seismic sequence.

- Based on the data that are recorded during the first 48 hours after the occurrence of the main shock, a completeness magnitude is estimated and a corresponding $\log \mathrm{N}$ vs $\mathrm{M}$ plotdiagram is created.

- Based on the complete data of the first 48 hours, a mean magnitude, $\mathrm{M}_{\mathrm{m}}$, is estimated and simultaneously a corresponding plot of $\mathrm{M}_{\mathrm{m}}$ vs time is generated.

- A mean strike azimuth is estimated based on the geographic distribution of the selected earthquakes (earthquakes contained in the region of interest, namely the seismogenic volume).

- Based on this strike azimuth, along-strike and strike-normal cross-sections of the focal area are constructed.

- A space-time distribution graph of the aftershocks is also created.

- Based on the complete data of the first 48 hours, a graph of the time distribution of the earthquakes is automatically generated.

From the diagrams generated after the application of the integrated program, the user can obtain preliminary but reliable information on the evolution of the seismic excitation. In particular he may examine the geographical distribution of the earthquakes (spatial distribution), the potential rupture area as calculated from the data of the first 48 hours (longitudinal section and time-space distribution) and assess whether or not the evolution of the excitation over time evolves normally (time distribution and mean magnitude).

\subsection{Parameters' Determination}

After the application of this software, several quantitative parameters estimated are examined:

$\underline{\text { XLVII, No } 3-1301}$ 
- The spatial distribution of the epicenters of the sequence roughly defines the seismogenic region. More specifically, the length of the fault, according to the magnitude of the mainshock, is estimated (Papazachos et al., 2004) (Equation 4) and then it is doubled in order to include all earthquakes that are considered as members of the sequence. This was because the automatically defined epicenters form a region almost double than the real one (Teza, 2011).

Equation 4

$\log L=0.51 M-1.85$

- The magnitude distribution of earthquakes of the sequence demonstrates the completeness magnitude and the values of the parameters $a, b$ of the G-R function. More specifically, the completeness magnitude is estimated based on the data of the first 48 hours in order to examine if this magnitude varies, through the evolution of the sequence, with time.

- The mean (average) magnitude distribution of the earthquakes of the sequence and its fluctuations are studied in order to identify possible changes over time. For this purpose, the data of the first 48 hours are used to determine the representative value of the mean magnitude and its standard deviation. Thereafter the magnitude of each new aftershock incorporated in the graph-plot in order to determine if that falls within the $68 \%$ confidence limits $\left(\mathrm{M}_{\mathrm{m}} \pm 1\right.$ standard deviation $)$.

- The longitudinal section of the seismic region of the sequence provides a reliable estimation of the length of the seismic fault. In this way it can be checked whether the estimated fault length agrees with the one theoretically calculated by Equation 4 . Moreover, the strike-normal cross-section provides information on the dipping direction of the fault.

- The time distribution of the earthquakes provides critical information on the normal (or not) evolution of the seismic sequence. In particular, through the use of Equation 2, both the coefficients of this relation and its $95 \%$ confidence limits (intervals) can be specified in order to delineate the deviations from this theoretical relation which can be considered as normal. These estimations are based on the complete data of the first 48 hours.

- The space-time distribution of earthquake epicenters of the sequence, in combination with the spatial distribution (seismicity map) can lead to valuable conclusions regarding the rupture propagation on the seismic fault, (e.g. unidirectional or bidirectional rupture, etc.).

\section{Software Application and Results}

An application of this software package, previously described, has been performed during the recent seismic sequence which occurred SE of Lemnos Island. The main shock occurred on 8 January 2013 14:16 GMT and its magnitude was M=5.9 (Figure 1).

The software was initially applied automatically, using as an input file a catalogue of earthquakes analysed by the software SeisComP. Due to shortage of data, a merged catalogue was eventually chosen to be used. This catalogue also incorporated manually elaborated data from AUTH and NOA. Therefore, the initial list of automatically analysed earthquake data was continuously supplemented with data derived by manual analysis. The software was activated periodically every 24 hours for a total duration of 9 days in order to obtain an objective view of the evolution of the sequence over time by checking for possible fluctuations of the values of the monitored parameters with the ones defined with the first 48 hours data. These repetitive daily applications allowed drawing conclusions in near real time sense about the evolution of the sequence.

In the present work, the values of the parameters as these were estimated 48 hours after the occurrence of the main earthquake (last event of the catalogue: 10/01/2013, 00:12:40 GMT) and for a period of 9 days after the occurrence of the main earthquake are presented (last event of the

$\underline{\text { XLVII, No } 3-1302}$ 
catalogue: 17/01/2013, 23:11:14 GMT). In particular, the space distribution, the time distribution, the magnitude distribution, the variation of mean magnitude, the longitudinal and cross section of seismogenic region and the space-time distribution of the sequence were examined. The maps and the parameters which were defined by using the first 48 hours data were considered as representative of the sequence (Figure 2). Therefore, the completeness magnitude was automatically defined as $M_{C}=2.2$, while the mean magnitude for events above $M_{C}$ was $M_{m}=2.75 \pm$ 0.44 . The spatial distribution of the epicentres of the first 48 hours revealed a linear distribution of the aftershocks volume, trending in an azimuth of $\sim \mathrm{N} 68^{\circ} \mathrm{E}$. The longitudinal section suggested a fault length of $\sim 15 \mathrm{~km}$, which is in a very good agreement with the length derived from the spatial distribution of the epicenters (see the map of Figure 2). The cross-section of the earthquake foci shows an almost vertical fault. Both the azimuth and the dip of the fault plane are in good agreement with FPS published by GCMT, http://www.globalcmt.org, (azimuth $239^{\circ}$, dip angle $80^{\circ}$, slip $178^{\circ}$ ). Finally, the space-time distribution of the aftershocks showed a clear unilateral rupture of the aftershocks, propagating in a NE direction. This evidence is also supported by the epicentral map, where the epicentre of the mainshock is located at the south westernmost edge of the seismogenic region.

The above procedure revealed the "identity" characteristics of the sequence, as they are quantitatively described by the employed parameters. Daily runs of the software allowed the frequent monitoring of the sequence's evolution, providing a clear picture of a normally evaluating aftershock activity. The values of the monitored parameters through this time-period (values in daily basis) are given in Table 1. Figure 3 gives a snap-shot of how the examined parameters varied up to the ninth day of the sequence. The final completeness magnitude was defined as $M_{C}=2.0$, while the mean magnitude of the aftershocks (following this completeness criteria) was $M_{m}=2.6$. The spatial distribution of the epicentres of the first 9 days clearly depicts the lineament of the aftershocks volume with an azimuth of $\sim \mathrm{N} 60^{\circ} \mathrm{E}$. The longitudinal section of the aftershocks foci (along this azimuth) continued to describe a fault length of $\sim 15 \mathrm{~km}$, while their strike-normal cross-section kept showing an almost vertical fault. The space-time distribution (and the epicentral map) of the aftershocks didn't change the picture obtained after the first 48 hours, showing unilateral rupture propagating in a NE direction (Figure 3).

\section{Discussion}

A software package to monitor seismic excitations in almost real-time sense was developed based on proposed definitions and semi-empirical formulations of certain aftershock sequence parameters, directly associated to the nature of the sequence. The software was tested on the recent sequence of the January $8^{\text {th }}, 2013$ earthquake, $M=5.9$, which occurred SE of the Lemnos island. The evolution of the sequence was daily monitored during the first nine days after its occurrence. Comparison of the graphs generated by this software 48 hours after the mainshock's occurrence with the respective graphs produced daily up to January $17^{\text {th }}$ showed that the values of the monitored parameters of the sequence remained almost constant, without exhibiting significant variations. This observation was strong evidence that the sequence under study evolved normally during the monitored time period, confirming the characterization of the 5.9 magnitude earthquake as a mainshock.

$\underline{\text { XLVII, No } 3-1303}$ 

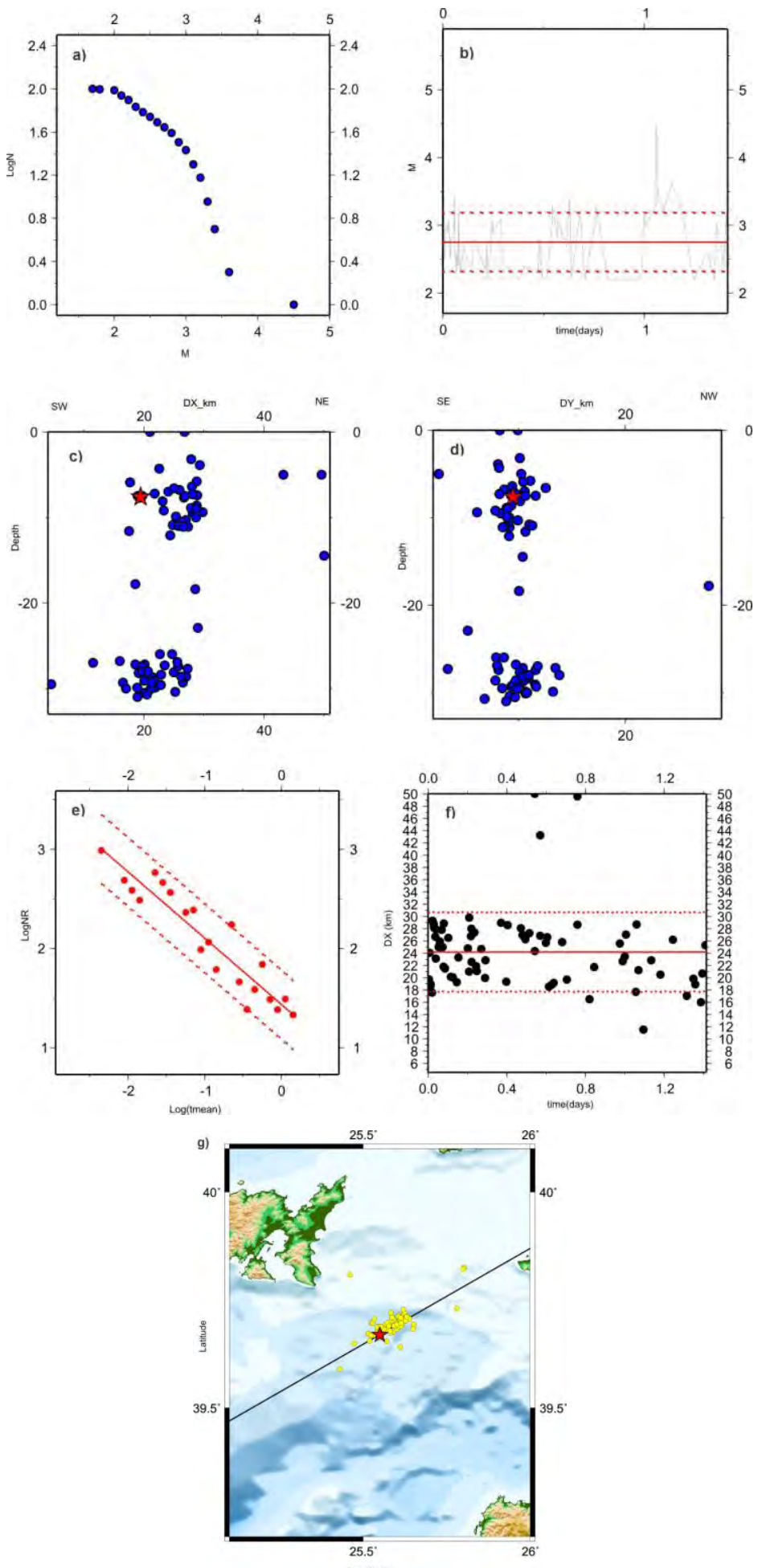

Figure 2 - Presentation of the software results, as estimated with the software application 48 hours after main shock: a) G-R distribution, b) mean magnitude, c) along-strike section, d) cross-strike section, e) time distribution, f) space-time distribution and g) seismicity map. 
Table 1- Values of the parameters calculated by the software application. $M_{c}$ is the magnitude of completeness, $M_{\text {mean }}$ the mean magnitude, $L$ the fault length.

\begin{tabular}{|c|c|c|c|}
\hline Software Applications & Parameter & $\begin{array}{c}\text { For the first } \\
48 \text { hours }\end{array}$ & $\begin{array}{l}\text { After } \\
\text { 9days }\end{array}$ \\
\hline \multirow{3}{*}{ G-R distribution } & $M_{c}$ & 2.2 & 2.0 \\
\hline & $b$ & 0.94 & 0.88 \\
\hline & $a$ & 4.08 & 4.12 \\
\hline \multirow{2}{*}{ Magnitude distribution } & $M_{\text {mean }}$ & 2.75 & 2.55 \\
\hline & SD & 0.44 & 0.46 \\
\hline Seismicity map & Azimuth & $\mathrm{N} 60^{\circ} \mathrm{E}$ & $\mathrm{N} 68^{0} \mathrm{E}$ \\
\hline Section along strike & $L(\mathrm{~km})$ & 13 & 15 \\
\hline \multirow[t]{2}{*}{ Time distribution } & $b$ & 0.67 & 0.66 \\
\hline & $a$ & 1.44 & 1.56 \\
\hline Time distribution $95 \%$ 1st & $a$ & 1.79 & 1.99 \\
\hline Time distribution $95 \%$ 2nd & $a$ & 1.09 & 1.14 \\
\hline \multirow{2}{*}{ Space-time distribution } & Mean $D X(\mathrm{~km})$ & 24.18 & 21.95 \\
\hline & $\mathrm{SD}(\mathrm{km})$ & 6.46 & 4.23 \\
\hline
\end{tabular}

A general conclusion that can be drawn from the present study is that the evaluation of the possible evolution of a seismic excitation, already in progress, may be feasible. However, in order to achieve this target, certain requirements must be fulfilled. A self-evident prerequisite is that a reliable database is available, which can be continuously updated in near real-time sense. Automatic locations will be its basic data-source but it will be also enriched by manually analysed events in order to improve the accuracy of the estimated focal parameters. Following this requirement, the application of the presented software can provide useful information to be used for a reliable evaluation of the possible evolution of the monitored seismic excitation. 

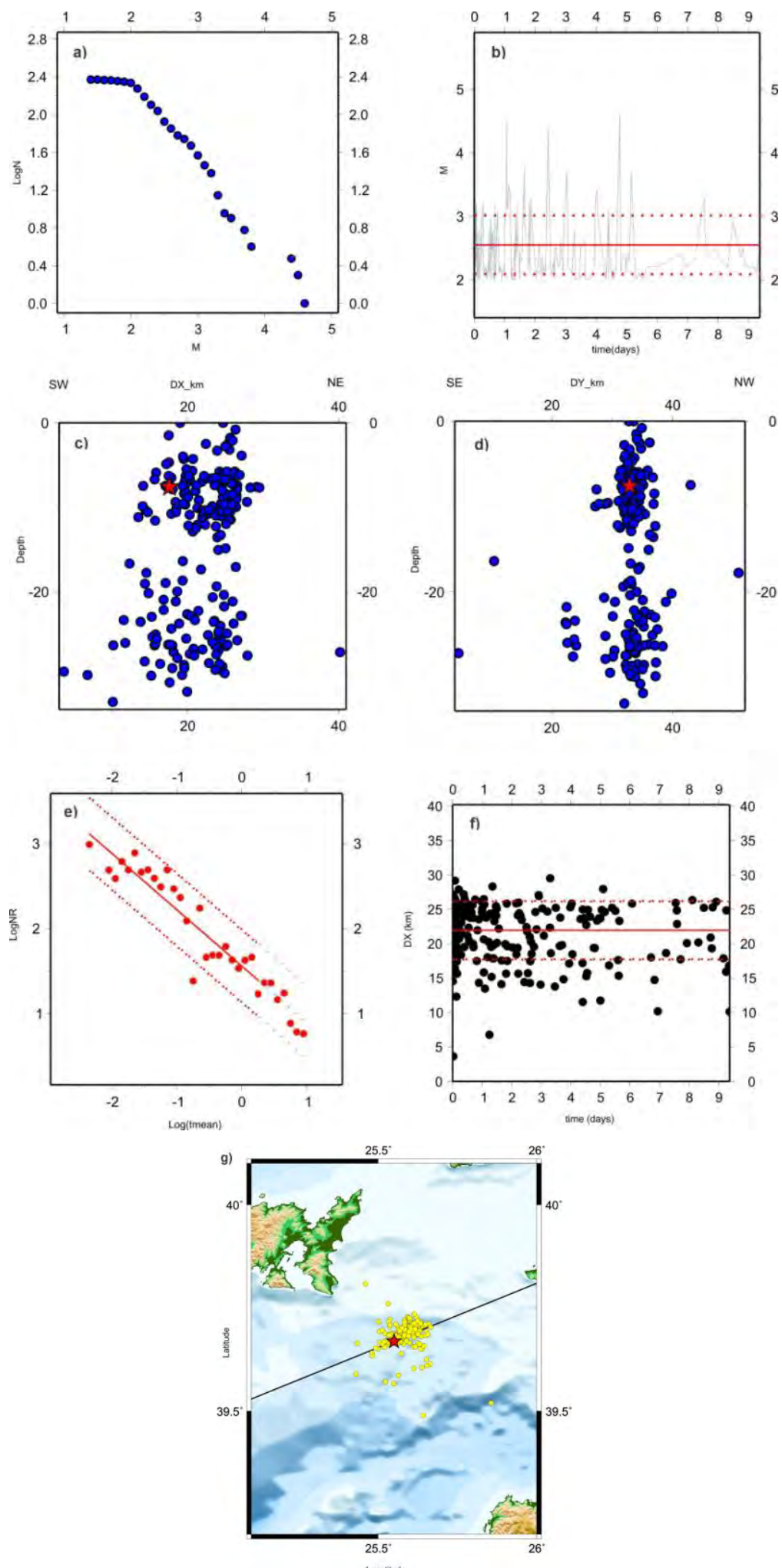

Figure 3 - Same as Figure 2 on the ninth day of the aftershock sequence.

$\underline{\text { XLVII, No } 3-1306}$ 


\section{Acknowledgments}

The maps were produced with the GMT software (Wessel and Smith, 1995). This research has been co-financed by the European Union (European Social Fund - ESF) and Greek national funds through the Operational Program "Education and Lifelong Learning" of the National Strategic Reference Framework (NSRF) - Research Funding Program: THALES. Investing in knowledge society through the European Social Fund. Project SEISMO FEAR HELLARC. Geophysics Department Contribution 808/2013.

\section{References}

Gutenberg B. and Richter C.F. 1944. Frequency of earthquakes in California, Bull. Seis. Soc. Am., 34, 185-188.

Mogi K. 1962. Study of elastic shocks caused by the fracture of heterogeneous materials and their relation to earthquake phenomena, Bull. Earthq. Res. Inst., Univ. Tokyo, 40, 125-73.

Nasu N. 1929. On the aftershocks of the Tango earthquake, Bull. Earthq. Res. Inst., 6, 245-332.

Omori F. 1894. On aftershocks of earthquakes, J. Coll. Sc. Imp. Univ. Tokyo, 7, 111-200.

Papazachos B.C. 1974. On certain aftershock and foreshock parameters in the area of Greece, Ann. Geofis., 27, 497-515.

Papazachos B.C., Scordilis E.M., Panagiotopoulos D.G., Papazachos C.B. and Karakaisis G.F. 2004. Global relations between seismic fault parameters and moment magnitude of earthquakes, Bulletin of the Geological Society of Greece, XXXVI, 3, 1482-1489.

Ranalli G. 1969. A statistical study of aftershock sequences, Ann. Geophys., 22, 359-397.

Teza E. 2011. Automated procedure to monitor and evaluate the evolution of seismic excitations, Msc. Thesis, Aristotle University, Thessaloniki, 190pp.

Wessel P. and Smith W. 1995. "New version of the Generic Mapping Tools", EOS, 76-329. 